\title{
Low Dose Cyclosporin A Therapy in Chronic Posterior Uveitis
}

\author{
H. M. A. TOWLER, A. M. CLIFFE, P. H. WHITING, ${ }^{*}$ and J. V. FORRESTER \\ Aberdeen
}

\begin{abstract}
Summary
Nine patients with chronic posterior endogenous uveitis of varying aetiology, not satisfactorily controlled with systemic corticosteroids alone, were treated with low dose oral Cyclosporin A (mean maintenance dose $4.0 \pm 1.1 \mathrm{mg} / \mathrm{kg} / \mathrm{day}$ ). Six of the nine patients also continued to receive oral prednisolone (15 mg/day or less). During a follow up period of 6-30 (mean 17) months, seven have shown sustained visual improvement. Nephrotoxicity was the major side effect with serum creatinine concentration (mean $\pm 1 \mathrm{SD}$ ) rising from $91 \pm 7 \mu \mathrm{mol} / \mathrm{l}$ to $115 \pm 13 \mu \mathrm{mol} / \mathrm{l}(0.01<\mathrm{p}<0.05)$ after the first twelve months of treatment. Other observed side effects have included taste disturbance, hypomagnesaemia, and hypertension.

Cyclosporin A treatment is of value in the management of severe intraocular inflammation, unresponsive to conventional therapy, but the optimum duration of therapy remains to be established and nephrotoxicity is the major dose limiting effect.
\end{abstract}

Chronic posterior uveitis is a significant cause of visual handicap in young and middle-aged adults, ${ }^{1}$ which often requires treatment with systemic corticosteroids or more powerful immuno-suppressive therapy. Cyclosporin A, a cyclic undecapeptide of fungal origin, which inhibits the production of interleukin-2 thereby inhibiting helper T-cell function, has been shown to be of value in both clinical2.3 and experimental ${ }^{4-6}$ studies of posterior uveitis. Other ocular conditions in which Cyclosporin A may be of clinical value include Mooren's ulcer, ${ }^{7}$ Behçet's disease ${ }^{8,9}$ Graves' ophthalmopathy, ${ }^{10-12}$ and corneal graft rejection. ${ }^{13,14}$ Considerable disquiet remains about the potential for toxicity of Cyclosporin $\mathrm{A}$ in these non life-threatening situations, notably nephrotoxicity, hepatotoxicity, and the risk of neoplasia with long-term treatment. ${ }^{15,16} \mathrm{We}$ describe our experience of low dose Cyclosporin A (CsA) treatment in nine patients with sight-threatening chronic intraocular inflammation which had not been adequately controlled with systemic corticosteroids.

\section{Patients and Methods \\ Study Group}

Clinical details of the study group are shown in Table I. Pars planitis and retinal vasculitis with associated cystoid macular oedema were the most common diseases

From: Departments of Ophthalmology and Clinical Biochemistry, ${ }^{*}$ University of Aberdeen, Medical School, Foresterhill, Aberdeen.

Correspondence to: Professor J. V. Forrester, Department of Ophthalmology, University of Aberdeen, Medical School, Foresterhill, Aberdeen AB9 2ZD

Presented at the Scottish Ophthalmological Club and Norwegian Ophthalmological Society Combined Meeting, October 1987, Aberdeen. 
Table I Cyclosporin A patient group (CMO = Cystoid Macular Oedema $)$

\begin{tabular}{|c|c|c|c|c|c|}
\hline Patient & Sex & Age & Diagnosis & $\begin{array}{c}\text { Maintenance dose } \\
\text { of } \operatorname{Cs} A(\mathrm{mg} / \mathrm{kg})\end{array}$ & $\begin{array}{l}\text { Follow up } \\
\text { (months) }\end{array}$ \\
\hline 1 & $\mathrm{~F}$ & 29 & Retinal Pigment Epitheliitis & 5.0 & 13 \\
\hline 2 & $\mathbf{M}$ & 37 & Retinal Vasculitis & 4.25 & 22 \\
\hline 3 & $\mathbf{M}$ & 41 & Sarcoidosis, Retinal Vasculitis & 5.5 & 26 \\
\hline 4 & $\mathrm{~F}$ & 58 & Pars Planitis, CMO & 2.5 & 16 \\
\hline 5 & M & 64 & Pars Planitis, CMO & 3.5 & 5 \\
\hline 6 & $\mathrm{~F}$ & 63 & Birdshot Choroidopathy, CMO & 4.0 & 14 \\
\hline 7 & $\mathbf{M}$ & 46 & Behçet's Disease, Scleritis, CMO & 2.75 & 5 \\
\hline 8 & M & 48 & Sarcoidosis, Retinal Vasculitis & 3.5 & 30 \\
\hline 9 & $\mathbf{M}$ & 18 & Pars Planitis, CMO & 5.0 & 24 \\
\hline Mean & & 44.8 & & 4.0 & $\overline{17}$ \\
\hline SD & & 15.0 & & 1.1 & 9 \\
\hline
\end{tabular}

requiring CsA therapy. Two patients with sarcoidosis and chronic posterior uveitis had no extraocular manifestations of sarcoidosis, the diagnosis being confirmed by the Kveim test. All patients had either failed to respond adequately to systemic corticosteroids (oral prednisolone) or had relapsed when the dose was reduced below $20 \mathrm{mg} /$ day. Steroid treatment had been continued for at least one year prior to introduction of CsA therapy. Three have discontinued prednisolone completely and six have continued on a low dose (10$15 \mathrm{mg}$ prednisolone/day). The mean patient age was 45 years and the mean duration of follow up 17 months. The clinical, visual, and biochemical parameters monitored before and during CsA treatment are shown in Table II and Appendix I.

\section{Cyclosporin A Regimen}

Treatment was commenced as a single oral dose of $10 \mathrm{mg} / \mathrm{kg} /$ day in the first four patients, but the induction dose was subsequently reduced to $5 \mathrm{mg} / \mathrm{kg} /$ day because of high whole blood levels. The maintenance dose, taken as a single oral dose in the evening, was thereafter adjusted to achieve a trough whole blood level of $300-800 \mathrm{ng} / \mathrm{ml}$ to minimise nephrotoxicity. Trough whole-blood levels of CsA were measured using a radioimmunoassay kit provided by Sandoz Ltd. The polyclonal antiCsA antibody could not distinguish between the parent compound and certain of its metabolites. CsA levels were measured at weekly intervals until stable and monthly thereafter. Patients were initially seen weekly following induction of CsA treatment in hospital and thereafter on a monthly basis.

\section{Results}

Clinical Response to CsA

Vision improved in eleven eyes, deteriorated in three, and remained static in one (Fig. 1). The intraocular inflammatory score showed no significant difference in visual outcome between patients receiving combination therapy of CsA and prednisolone or CsA alone. Three eyes were excluded from analysis for the following reasons: one eye blind following rhegmatogenous retinal detachment, one eye densely amblyopic since childhood, and one eye with no clinical evidence of intraocular inflammation throughout the study. Two cases illustrate the benefit of CsA therapy.

\section{Patient 8}

(Figs. 2 and 3)

A 48 year old man with bilateral chronic posterior and anterior uveitis due to sarcoidosis, proven by Kveim test, showed a

Table II Parameters monitored during Cyclosporin A therapy

Serum electrolytes, glucose, magnesium

Urea, creatinine, urate

Liver function tests

Full blood count

Blood pressure

Urinalysis

Visual acuity

Intraocular inflammatory score 


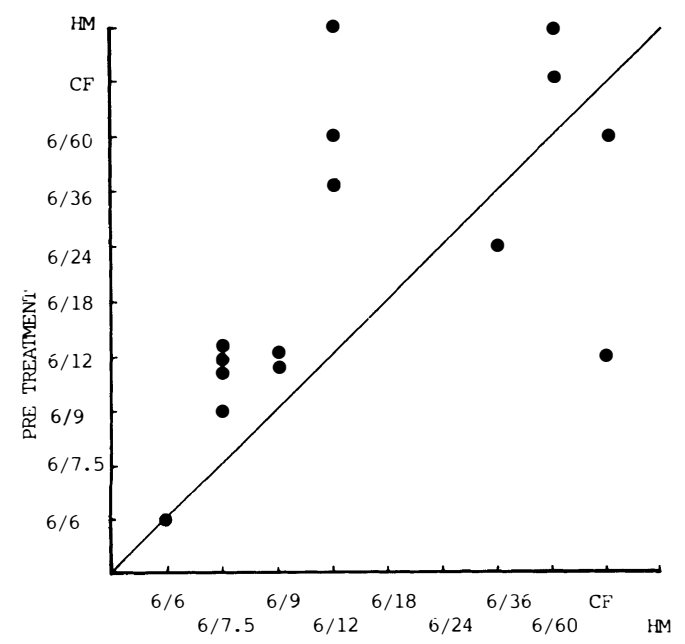

POST TREATMENT CYCLOSPORIN A

VISUAL OUTCOME

Fig. 1 Visual acuity change following Cyclosporin A therapy.

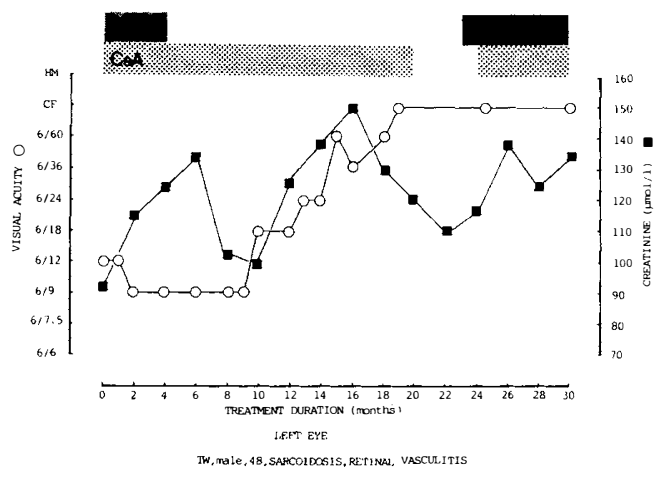

Fig. 2 Left visual acuity and serum creatinine changes during Cyclosporin A therapy (Pred=Prednisolone).

poor response to oral prednisolone. He had developed a dense secondary cataract in the right eye which precluded visualisation of the vitreous or fundus. Following the introduction of CsA therapy, his left visual acuity improved and his steroids were discontinued (Fig. 2). He subsequently developed a left posterior subcapsular cataract, and proceeded to right extracapsular cataract extraction with posterior chamber intaocular lens implant, following which his right visual acuity improved to 6/7.5 (Fig. 3). Eight months later his CsA was stopped but his uveitis then increased in activity, requiring reintroduction of $\mathrm{CsA}$ and prednisolone ( $20 \mathrm{mg} /$ day), following which his vision again improved. The left cataract has increased in density and he is awaiting surgery. On a maintenance dose of $3.5 \mathrm{mg} / \mathrm{kg} /$ day CsA, his serum creatinine has fluctuated between 110-140 $\mu \mathrm{mol} / \mathrm{l}$, but fell to the upper limit of the reference range on interruption of CsA therapy.

\section{Patient 7}

(Figure 4)

A 48 year old man with known Behçet's disease developed scleritis of his left eye, associated with vitritis and cystoid macular oedema. His scleritis would consistently reactivate on reducing his dose of prednisolone below $20 \mathrm{mg} /$ day, and he was, therefore, commenced on combination CsA and pred-

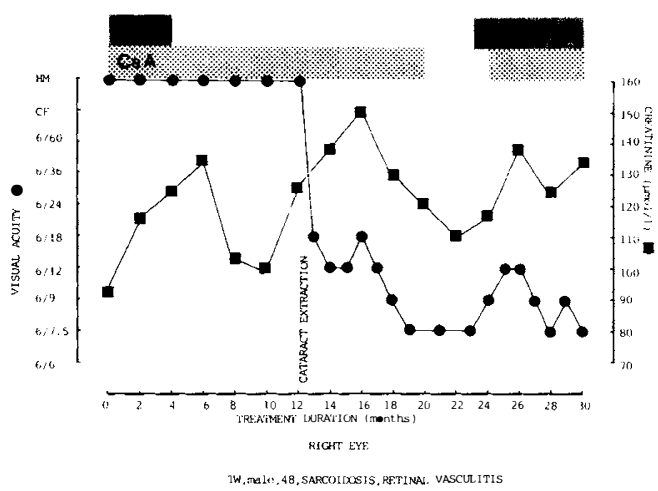

Fig. 3 Right visual acuity and serum creatinine changes during Cyclosporin A therapy (Pred=Prednisolone).

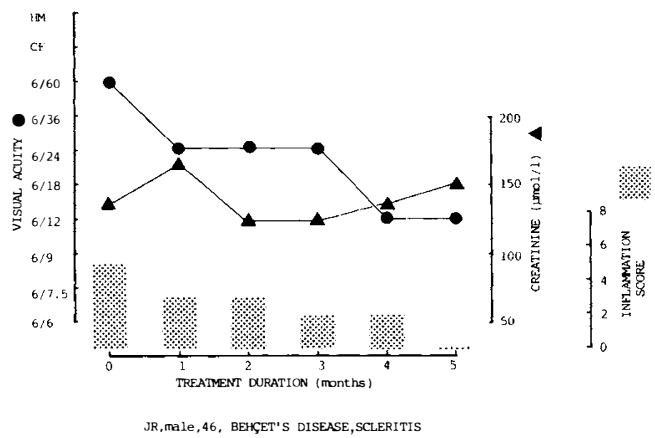

Fig. 4 Left visual acuity, serum creatinine, and intraocular inflammation changes during Cyclosporin A therapy. 
nisolone therapy with a maintenance dose of CsA of $2.75 \mathrm{mg} / \mathrm{kg} /$ day. His left visual acuity has improved from $6 / 60$ to $6 / 12$, the intraocular inflammatory score fallen, and serum creatinine fluctuated between $120-160 \mu \mathrm{mol} / \mathrm{l}$ (Fig. 4). His dose of prednisolone has subsequently been reduced to $9 \mathrm{mg} /$ day.

\section{Cyclosporin A Toxicity}

The side effects of treatment are shown in Table III. Nephrotoxicity was the most common toxic effect, as evidenced by the gradual rise in serum creatinine over the first 18 months which was significant $(0.01<\mathrm{p}<0.05)$ after 12 months (Fig. 5). Reductions of other parameters of renal function including lithium clearance which reflects renal tubular dysfunction were also observed during this period (unpublished observations). Hypomagnesaemia was usually transient with only one patient requiring oral supplements for the treatment of troublesome cramps. Two patients required treatment for hypertension developing after institution of CsA therapy. One patient already receiving nifedipine, atenolol, and bendrofluazide therapy for hypertension and who had shown no impairment of control of her hypertension recently suffered a cerebellar infarct. One man developed an erythematous, macular rash resembling pityriasis versicolor and nail thickening, particularly of the toes, suggesting fungal disease though skin scrapings and nail clippings failed to demonstrate any pathogenic fungi. In addition, one patient has developed Type II diabetes mellitus, more likely due to obesity and concurrent administration of a thiazide diuretic than any diabetogenic effect

Table III Cyclosporin A toxicity

\begin{tabular}{ll}
\hline Nephrotoxicity & $(8)$ \\
Hypomagnesaemia & $(4)$ \\
Taste disturbance & $(4)$ \\
Hirsutism & $(4)$ \\
Hypertension & $(2)$ \\
Paraesthesiae & $(2)$ \\
Rashes & $(2)$ \\
Gingivitis & $(1)$ \\
Cramps & $(1)$ \\
Nail abnormality & $(1)$ \\
Hepatotoxicity & $(0)$ \\
Neoplasia & $(0)$ \\
\hline
\end{tabular}

of CsA. ${ }^{17}$ Increased hair growth was noted by four patients, but has been troublesome in only one woman. Overt hepatotoxicity has not been observed.

\section{Discussion}

The results of this study confirm previous clinical reports of the value of CsA in the management of chronic intraocular inflammation. The overall clinical visual improvement contrasts with the lack of change in the intraocular inflammatory score in both the anterior and posterior segments of the eye. Anterior uveitis developed in two patients only after the introduction of CsA therapy, and, in a further four patients, control of anterior chamber activity necessitated the intermittent use of topical corticosteroids. This observation is at odds with the findings of Nussenblatt and colleagues ${ }^{2}$ who noted a decrease in the cellular activity in both the anterior chamber and vitreous. Binder et al. ${ }^{9}$ also noted a reduction in intraocular inflammation, though their scoring system did not include the anterior segment of the eye. ${ }^{18}$ This discrepancy may reflect the difficulty of accurately measuring intraocular inflammation, though some further refinements on Hogan and Kimura's system ${ }^{19,20}$ have been made. $^{21}$

Nephrotoxicity remains the most serious problem, despite a lower maintenance dose than that employed in other studies. Palestine et al. ${ }^{22}$ have demonstrated significant renal histopathological changes in a similar group of patients but who had received a maintenance CsA dose of $10 \mathrm{mg} / \mathrm{kg} /$ day over a period of 24 months. Svenson et al. ${ }^{23}$ however, have shown similar histopathological changes in CsA treated patients with autoimmune disease (two with uveitis) in whom a lower maintenance CsA dose of $2.5-7.5 \mathrm{mg} / \mathrm{kg} / \mathrm{day}$ was employed. The latter group have suggested that the cumulative dose of CsA may be an important factor in determining nephrotoxicity, and this is supported by Klintmalm et al. ${ }^{24}$ who reported that in CsA treated renal allograft patients maintenance CsA doses of $2.3-10.7 \mathrm{mg} / \mathrm{kg}$ contributed little to renal damage which was better correlated with high cumulative dosage in the first six months of treatment. Only one patient in our group has 


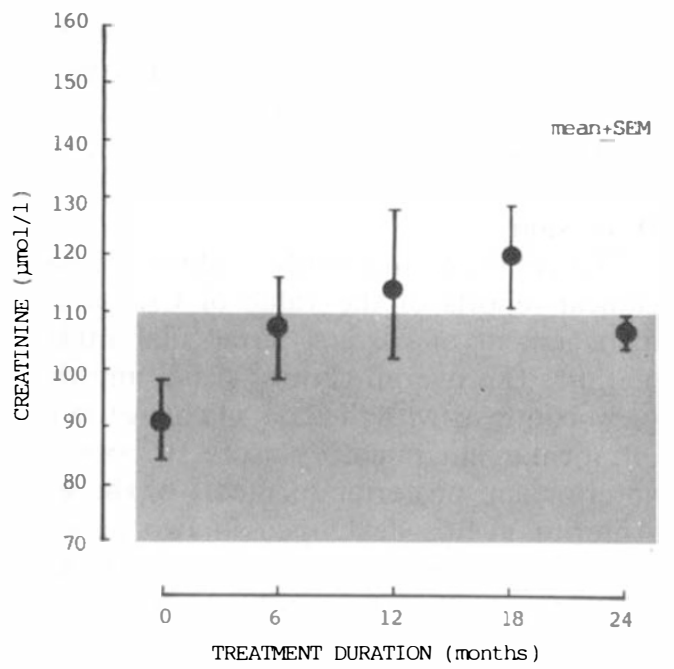

Fig. 5 Serum creatinine changes during Cyclosporin A therapy.

temporarily discontinued CsA therapy, but it was gratifying to note that his serum creatinine returned to within the reference range, along with improvement in other parameters of proximal renal tubule function, including enzymuria and proteinuria. The use of divided daily doses of CsA may be a less nephrotoxic regimen than single daily dosage due to lower peak levels but it is associated with a much higher incidence of gingival problems, ${ }^{9}$ which were seen in only one patient in this series.

Combination therapy of CsA and corticosteroids has been shown to be of benefit in ophthalmic Graves' Disease. ${ }^{11.12}$ Kahaly et al. ${ }^{11}$ found combination therapy more successful than prednisone alone, whereas Utech et $a l .{ }^{12}$ found combination therapy more successful than CsA alone. Both studies employed a similar induction dose as this study, but the maintenance doses were not reported. Any change in renal function returned to normal upon cessation of CsA therapy. It is interesting to note that the two patients in our study who required antihypertensive therapy also received CsA and prednisolone in combination as did four subjects in Kahaly's group who subsequently developed hypertension. Further study is required to determine whether hypertension is a more significant adverse effect of combination therapy with oral corticosteroid than CsA therapy alone. Both patients who had ocular sarcoidosis in this series demonstrated improvement in visual acuity and control of intraocular inflammation which contrasts with the lack of efficacy of CsA noted in pulmonary sarcoidosis. ${ }^{25}$

No patient in our study has discontinued CsA therapy because of toxicity, although the dosage has required modification. The frequency of relapse remains to be established on cessation of therapy and several patients are now tailing off by monthly decrements of $50 \mathrm{mg}$. Binder et al. ${ }^{9}$ noted a high frequency of recurrence of Behçet's disease activity on reducing the CsA dose below $7 \mathrm{mg} / \mathrm{kg} /$ day, and, more worryingly, the severity was often greater than prior to CsA treatment. Whether maintenance of a longer period of quiescence of disease activity by CsA treatment will reduce the frequency of relapse or not has yet to be evaluated.

Low-dose CsA treatment, either as monotherapy or in combination with oral corticosteroids ( $<15 \mathrm{mg}$ prednisolone), has proved to be of visual benefit in our group of patients with severe chronic intraocular inflammation which had responded poorly to conventional therapy. Nephrotoxicity is the major doselimiting side effect and further study of its aetiology, monitoring, and reversibility is required.

Appendix 1. Intra-ocular inflammatory score

$$
\begin{gathered}
\text { Anterior Segment } \\
\text { Cells } 0-4 \\
\text { Flare } 0-4 \\
\text { Keratic precipitates } 0-1 \\
\text { Posterior synechiae } 0-1 \\
\text { Posterior Segment } \\
\text { Vitreous cells } 0-4 \\
\text { Vitreous flare } 0-4 \\
\text { Macular oedema } 0-2 \\
\text { Retinal vasculitis } 0-1 \\
\text { Focal chorioretinal nodules } 0-1
\end{gathered}
$$

(Am. J. Ophthalmol. 1959, 47(Suppl.), 155-176.)

\section{References}

${ }^{1}$ Department of Health and Social Security: Blindness and partial sight in England 1969-1976. London: HMSO, 1979. (Reports on Public Health and Medical Subjects No. 129).

${ }^{2}$ Nussenblatt RB, Palestine AG, Rook AH et al:: 
Treatment of intraocular inflammatory disease with Cyclosporin A. Lancet 1983, ii: 235-38.

${ }^{3}$ Nussenblatt RB, Palestine AG, Chan CC: Cyclosporin A therapy in the treatment of intraocular inflammatory disease resistant to systemic corticosteriods and cytotoxic agents. Am J Ophthalmol 1983, 96: 275-82.

${ }^{4}$ Nussenblatt RB, Rodrigues MM, Wacker WB. et al.: Cyclosporin A: Inhibition of experimental autoimmune uveitis in Lewis rats. J Clin Invest 1981, 67: 1228-31.

${ }^{5}$ Striph G, Doft B, Rabin B, Johnson B: Retinal S antigen induced uveitis: the efficacy of cyclosporine and corticosteroids in treatment. Arch Ophthalmol 1986, 104: 114-17.

${ }^{6}$ Stanford MR, Atkinson E, Kasp E, Dumonde DC: Modulation of experimental retinal vasculitis using dexamethasone, cyclosporin A, and prazosin. Eye 1987, 1: 626-31.

${ }^{7}$ Hill JC and Potter P: Treatment of Mooren's ulcer with cyclosporin A: report of three cases. $\mathrm{Br} \mathrm{J}$ Ophthalmol 1987, 71: 11-15.

${ }^{8}$ Müftüoğlu AÜ, Pazarli H, Yurdakul S. et al.: Short term cyclosporin A treatment of Behçet's disease. Br J Ophthalmol 1987, 71: 387-90.

${ }^{9}$ Binder AI, Graham EM, Sanders MD, Dinning W, James DG, Denman AM: Cyclosporin A in the treatment of severe Behçet's uveitis. Br J Rheumatol 1987, 26: 285-91.

${ }^{10}$ Weetman AP, McGregor AM, Ludgate M. et al.: Cyclosporin A improves Graves' ophthalmopathy. Lancet 1983, ii: 486-9.

${ }^{11}$ Kahaly G, Schrezenmeir J, Krause U. et al.: Cyclosporin and prednisone $\mathrm{v}$. prednisone in treatment of Graves' ophthalmopathy: a controlled, randomised and prospective study. Eur J Clin Invest 1986, 16: 415-22.

12 Utech C, Wulle KG, Bieler EU. et al.: Treatment of severe Graves' ophthalmopathy with cyclosporin A. Acta Endocr 1985, 110: 493-8.

${ }^{13}$ Coster DJ, Shepherd WF, Chin Fook T. et al.: Prolonged survival of corneal allografts in rabbits treated with cyclosporin A. Lancet 1979, ii: 688-9.
${ }^{14}$ Bell TAG, Easty DL, McCullagh: A placebo-controlled blind trial of cyclosporin $\mathrm{A}$ in prevention of corneal graft rejection in rabbits. $\mathrm{Br} J$ Ophthalmol 1982, 66: 303-8.

${ }^{15}$ Bennett WM and Norman DJ: Action and toxicity of cyclosporine. Ann Rev Med 1986, 37: 215-24.

${ }_{16}$ Palestine AG, Nussenblatt RB, Chan CC: Side effects of systemic cyclosporine in patients not undergoing transplantation. Am J Med 1984, 77: 652-6.

${ }^{17}$ Bending JJ, Ogg CS, Viberti GC: Diabetogenic effect of cyclosporin. Br Med J 1987, 294: 401-2.

${ }_{18}$ Dumonde DC, Kasp-Grochowska E, Graham EM, Sanders MD, Faure JP, de Kozak Y: and van Tuyen V. Anti-retinal autoimmunity and circulating immune complexes in patients with retinal vasculitis. Lancet 1982, ii: 787-92.

${ }^{19}$ Hogan MJ, Kimura SJ and Thygeson P: Signs and symptoms of uveitis. I. anterior uveitis. Am J Ophthalmol 1959, 47 (Suppl.): 155-70.

${ }^{20}$ Kimura SJ, Thygeson P, Hogan MJ: Signs and symptoms of uveitis. II. Classification of the posterior manifestations of uveitis. Am J Ophthalmol 1959, 47 (Suppl.): 171-6.

${ }^{21}$ Nussenblatt RB, Palestine AG, Chan CC, Roberge F: Standardization of vitreal inflammatory activity in intermediate and posterior uveitis. Ophthalmology 1985, 92: 467-71.

22 Palestine AG, Austin HA, Balow JE. et al.: Renal histopathological alterations in patients treated with cyclosporine for uveitis. N Eng J Med 1986, 314: 1293-8.

${ }^{23}$ Svenson K, Bohman SO, Hallgren R: Renal interstitial fibrosis and vascular changes. Occurrence in patients with autoimmune diseases treated with Cyclosporine. Arch Int Med 1986, 146: 2007-10.

${ }^{24}$ Klintmalm, G, Bohman S, Sundelin B, Wilczek H: Interstitial fibrosis in renal allografts after 12 to 46 months of cyclosporin treatment: beneficial effect of low doses in early post-transplantation period. Lancet 1984, ii: 950-4.

${ }^{25}$ Rebuck AS, Sanders BR, MacFadden DK. et al.: Cyclosporin in pulmonary sarcoidosis. Lancet 1987, i: 1486 . 